\title{
Correction to: Identification of iron ore brands by multi-component analysis and chemometric tools
}

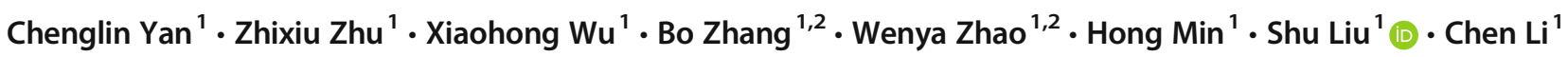

Received: 15 June 2021 / Accepted: 15 June 2021 / Published online: 6 July 2021

(C) Springer-Verlag GmbH Germany, part of Springer Nature 2021

\section{Correction to: Analytical and Bioanalytical Chemistry} https://doi.org/10.1007/s00216-021-03422-4

The authors would like to call the reader's attention to the fact that, unfortunately, there were two errors regarding Fig. 2 and Fig. 4.

(b) and (e) of Fig. 2 did not match the $\mathrm{Al}_{2} \mathrm{O}_{3}$ content and $\mathrm{P}$ content, but repeated the content of (c) and (i). The longitudinal coordinate axis in Fig.4 (b), (c), (d) should be labeled as ' $\omega(\mathrm{CaO}+\mathrm{MgO}) / \omega\left(\mathrm{SiO}_{2}+\mathrm{Al}_{2} \mathrm{O}_{3}\right)$ ', instead of ' $\omega(\mathrm{CaO}+\mathrm{Mg}) /$ $\omega\left(\mathrm{SiO}_{2}+\mathrm{Al}_{2} \mathrm{O}_{3}\right)^{\prime}$. Thus, Fig. 2 and Fig. 4 have been replaced with the corrected version shown below. These corrections have no effect on any other results published in the article, and do not affect the discussion or any of the published conclusions.

The online version of the original article can be found at https://doi.org/ $10.1007 / \mathrm{s} 00216-021-03422-4$

\footnotetext{
Shu Liu

liu_shu@customs.gov.cn

li_chen@customs.gov.cn

1 Technical Center for Industrial Product and Raw Material Inspection and Testing of Shanghai Customs, Shanghai 200135, China

2 College of Science, University of Shanghai for Science and Technology, Shanghai 200093, China
}

$\triangle$ Chen Li 

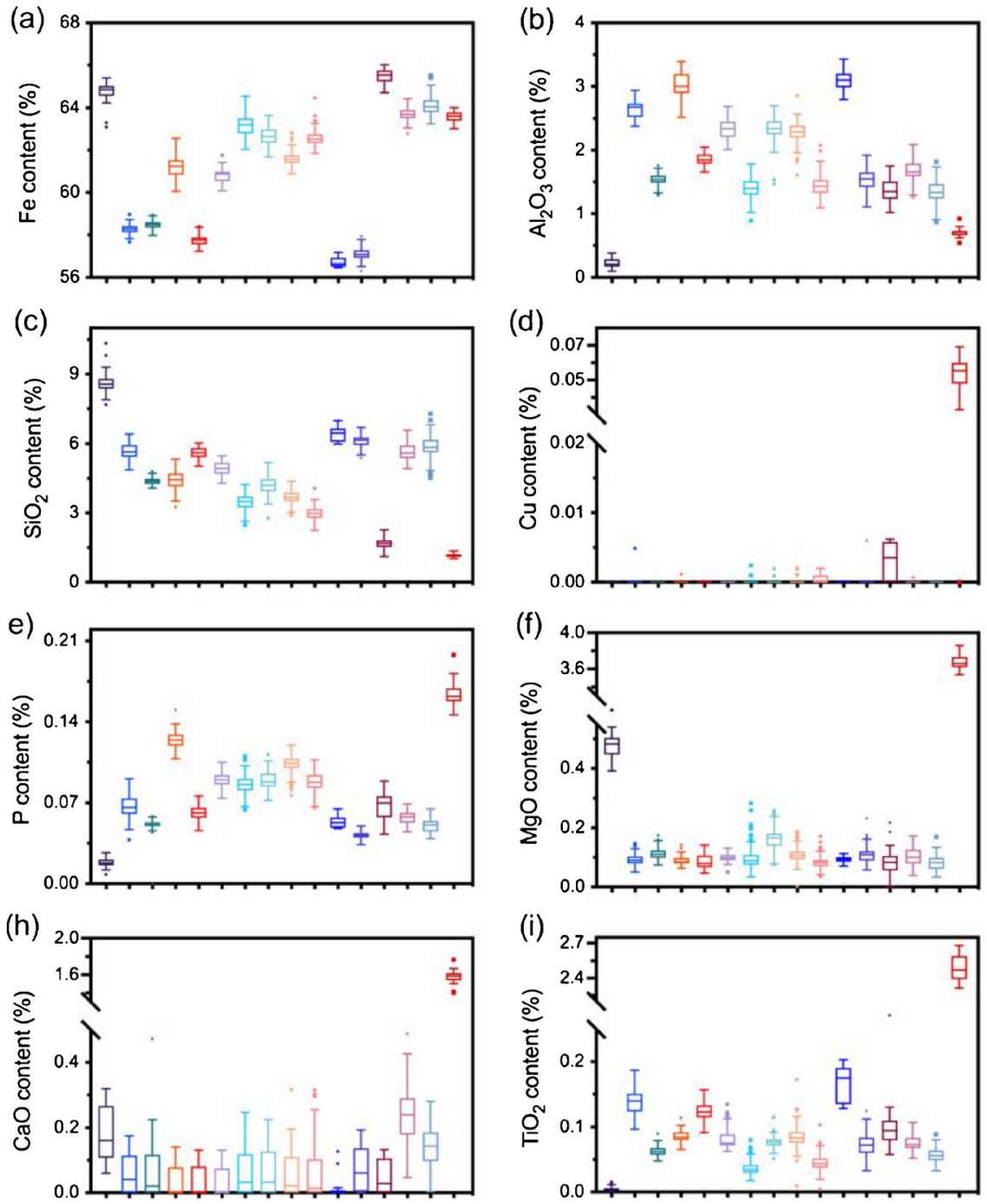
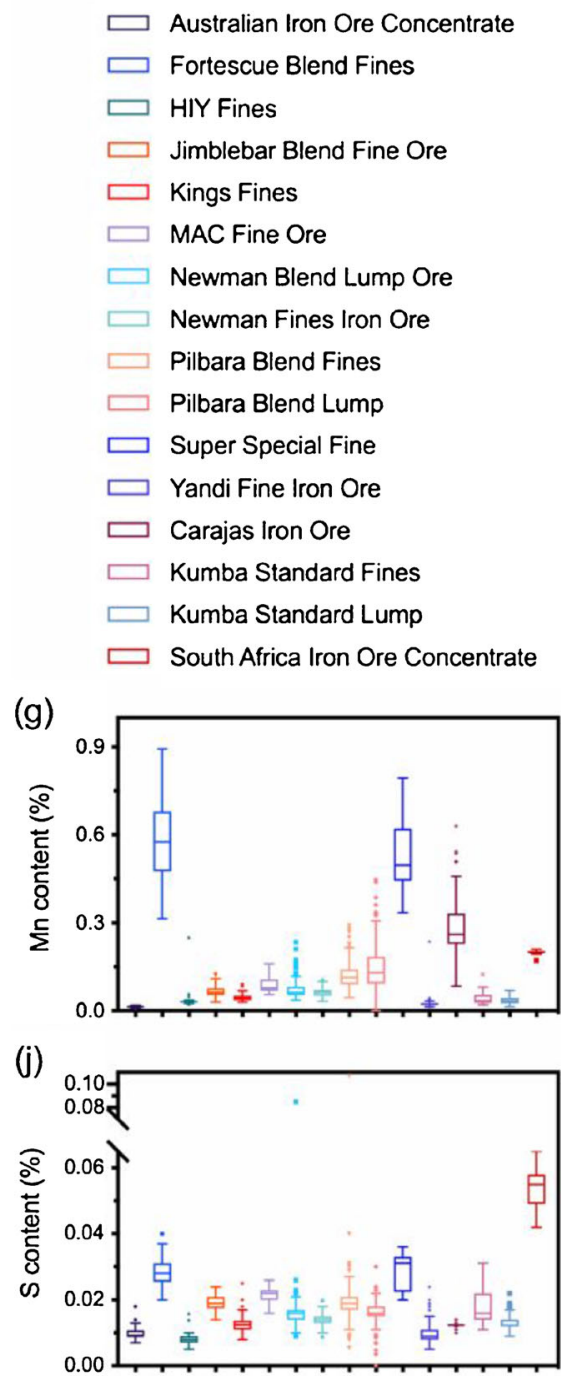

Fig. 2 Boxplots showing the distribution of (a) $\mathrm{Fe},(\mathbf{b}) \mathrm{Al}_{2} \mathrm{O}_{3}$, (c) $\mathrm{SiO}_{2}$, (d) $\mathrm{Cu},(\mathbf{e}) \mathrm{P},(\mathbf{f}) \mathrm{MgO},(\mathbf{g}) \mathrm{Mn},(\mathbf{h}) \mathrm{CaO}$, (i) $\mathrm{TiO}_{2}$, and (j) $\mathrm{S}$ contents in iron ores of different brands 
(a)

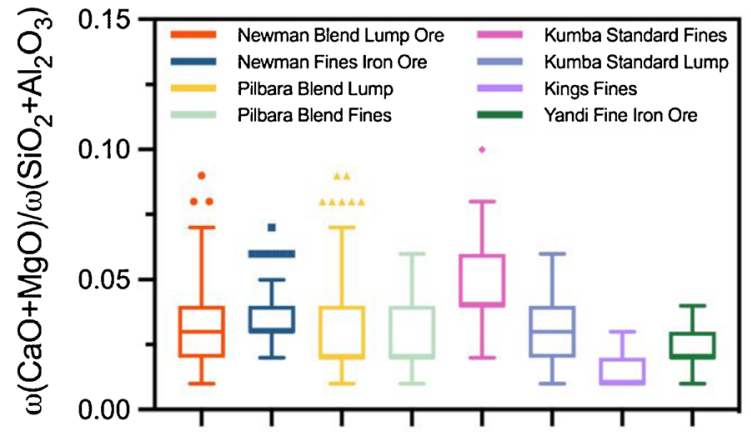

(c)

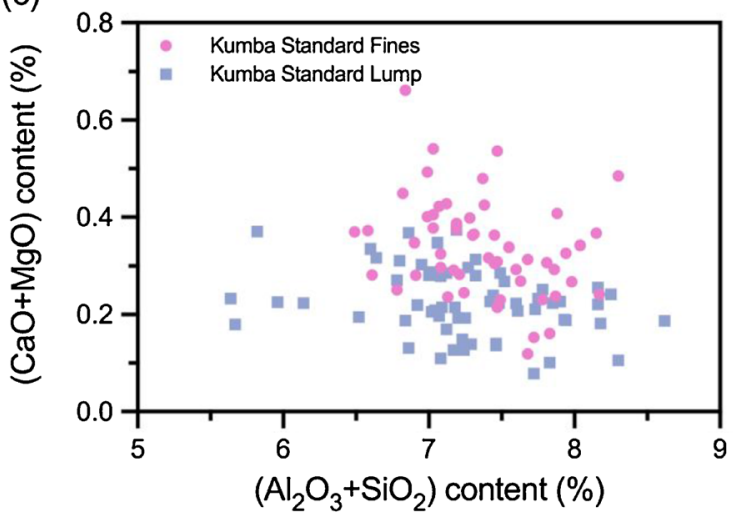

(b)

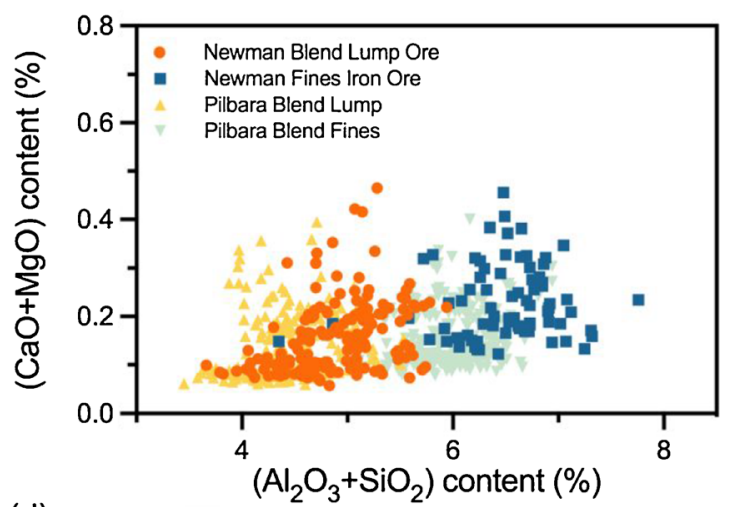

(d)

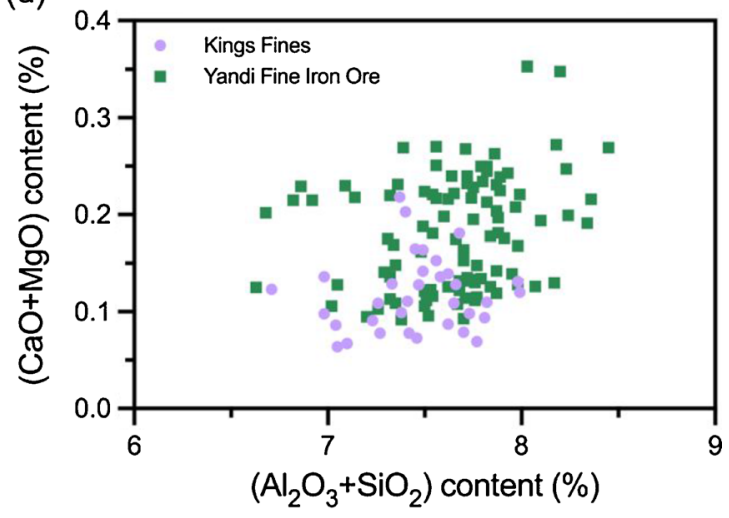

Fig. 4 The acidity and alkalinity of iron ore according to their brand

The original article has been corrected.

Publisher's note Springer Nature remains neutral with regard to jurisdic-

tional claims in published maps and institutional affiliations. 